\title{
Lithium Induced Toxicity in Rats: Blood Serum Chemistry, Antioxidative Enzymes in Red Blood Cells and Histopathological Studies
}

\author{
Mohammad Ahmad, ${ }^{*, a}$ Yasser Elnakady, ${ }^{b}$ Muhammad FarooQ, ${ }^{b}$ and Muhammad WadaAn ${ }^{b}$ \\ ${ }^{a}$ Department of Applied Medical Sciences, Community College, King Saud University; P.O. Box 28095, Riyadh-11437, \\ Saudi Arabia: and ${ }^{b}$ Department of Zoology, College of Science, Chair of Advanced Proteomics and Cytomics Research, \\ King Saud University; P.O. Box 2455, Riyadh-11451, Saudi Arabia.
}

Received June 28, 2010; accepted November 19, 2010; published online December 1, 2010

Lithium is commonly used in treating mental disorders and bipolar diseases. As physicians frequently keep the patients on long-term lithium therapy, awareness of the numerous side effects and pathogenesis of this lightest alkali metal is needed for such treatments. The present study was designed to evaluate the toxic effect of small doses of lithium chloride in male Wistar rats. The oral administration of lithium chloride $(15,30 \mathrm{mg} / \mathrm{kg} \mathrm{body} \mathrm{wt)}$ for 7 weeks through their drinking water elicited a significant alteration in their body weight and blood serum chemistry. The serum enzyme levels of alkaline phosphatase (ALP), high density lipoprotein (HDLP), and creatinine kinase (CK) were diminished, whereas the level of serum urea and glucose were elevated in the lithium treated animals, depicting the disturbed general physiological status. Furthermore, a marked inhibition in the levels of serum alanine and aspartate transaminases (ALT and AST) reflected a stimulating transamination reaction in hepatic and renal tissues. Lithium exposure also reduced the glutathione (GSH) level and stimulated the lipid peroxidation (LPO) level in the rat blood cells, indicating oxidative stress in the red blood cells due to lithium exposures. The histopathological observations of the liver and kidney tissues revealed many deformities and histological alterations due to lithium treatment. The results of present study suggest that small doses of lithium induce toxicity in rat blood as well as in liver and kidney tissues. However, the precise mechanism of lithium toxicity is still incompletely understood.

Key words lithium toxicity; rat; blood oxidative stress enzyme; blood serum chemistry; organ histopathology

Lithium is being used worldwide over the past few years as an important drug for the treatment and prophylaxis of mental disorders like mania and depression ${ }^{1,2)}$ and bipolar manic-depressive psychosis. ${ }^{3)}$ However, prolonged treatment with therapeutic doses of lithium induces substantial toxic effects. ${ }^{4)}$ Extensive usage of lithium and its compounds in pharmaceuticals, dehumidifying and air conditioning units, ceramics and metallurgical processes, lubricants and in a number of chemical and biological laboratories brings this lightest alkali metal in close contact of human. ${ }^{5}$

Toxicity of lithium may be caused while taken as medicine. $^{6)}$ Lithium salts cause ocular side effects, ${ }^{7)}$ polyuria, polydipsia, loss of body mass ${ }^{8)}$ and impaired renal concentration capacity after water deprivation. ${ }^{9}$ It is easily absorbed from gut, distributed readily throughout the body, and excreted almost entirely by the kidneys. ${ }^{10,11)}$ Lithium is considered to affect metabolism, neuronal communication, and cell proliferation. ${ }^{12)}$ Lithium effects have been investigated in detail on the brain, intestine, thyroid, and liver functions. ${ }^{13)}$ Neurological features may be encountered early, including drowsiness, slurred speech, psychomotor slowing, and impaired memory and, in severe cases, seizures, coma and death. ${ }^{14)}$ Lithium has also been reported to affect nerve excitation and affect the synthesis, activation, and inactivation of various neurotransmitters such as norepinephrine, serotonin, and dopamine. ${ }^{15-17)}$ Lithium is considered of being nephrotoxic ${ }^{18)}$ and has been used for inducing nephrogenic diabetes insipidus (NDI) in rats for experimental studies. ${ }^{19)}$ Lithium has the potential of inducing most of the adverse effects in rat blood, ${ }^{13)}$ liver $^{20)}$ and lungs. ${ }^{21)}$ Furthermore, lithium also induces oxidative stress in rat brain ${ }^{22)}$ and rat red blood cells (RBCs) ${ }^{13)}$ Lithium treatment has been shown to affect membrane dynamics of RBCs. ${ }^{23)}$
Although the security range of lithium's therapeutic window for human clinical use has been established between: 0.6 to $1.2 \mathrm{mmol} / 1$ serum levels this does not exclude the occasional toxic consequences of lithium. ${ }^{24)}$ The measurement of serum lithium concentration, which is the diagnostic method currently used to monitor lithium levels in bipolar patients, seems to be inaccurate since it has been pointed that lithium serum concentration did not satisfactorily reflect the tissue level. ${ }^{24)}$ New methods to predict the best lithium dosages for patients are required to allow the growing clinical use of lithium salts. These findings highlight the toxicity of lithium and emphasize that there are a number of features on the clinical use of lithium that are yet to be revealed. Thus, the present study, carried out in rats, is a contribution to explore physiological mechanisms underlying lithium toxicity in blood chemistry and in various organ tissues at histopathological level.

\section{MATERIALS AND METHODS}

Animals Male albino Wistar rats (4-6 weeks old) weighing 125-150g, were obtained from animal house colony of the College of Pharmacy, King Saud University, Riyadh. All experimental procedures were conducted in accordance with the institutional guidelines for the care and use of laboratory animals and were in accordance with the local animal care and ethics committee instructions. The animals were housed in polypropylene cages in the departmental animal house under hygienic conditions in an air conditioned room controlled at $22 \pm 2{ }^{\circ} \mathrm{C}, 55 \pm 5 \%$ humidity and with a 12-h light/dark cycle. The animals were maintained with the standard laboratory feed and water, ad libitum, throughout the period of experimentation. 
Experimental Design All 30 male Wistar rats were assigned to 3 experimental treatment groups at random and were used after one week of acclimatization to the laboratory conditions. Animals in group 1 served as controls and were given standard laboratory feed and water. Animals in groups 2 and 3 (lithium treated) were given lithium in the form of Lithium chloride $\left(\mathrm{LiCl}_{2}\right.$, Winlab) mixed in drinking water at a dose level of $15 \mathrm{mg}$ and $30 \mathrm{mg} \mathrm{Li} / \mathrm{kg}$ body weight (representing as Low Lithium and High Lithium doses respectively in all figures and tables of the present study). All treatments were given for 7 weeks. The dose and time of $\mathrm{LiCl}_{2}$ administration was selected on the basis of previously published literature and on the basis of pilot studies conducted in our laboratory where significant changes were observed. Furthermore, the doses of $\mathrm{LiCl}_{2}$ formed the only source of drinking fluid of the treated groups of animals and were available $24 \mathrm{~h}$ for a period of seven weeks. Fresh $\mathrm{LiCl}_{2}$ doses were prepared and replaced every alternate day.

Body and Organ Weight The body weight of all animals was recorded on day one of lithium treatment (before administering the first dose) and on the last day of total exposure period (seven weeks). The wet weight of internal organs was also recorded at the end of the exposure period as described below.

Collection of Blood Samples for Assays After the lithium exposure period the animal's blood samples were collected under light anesthesia with ether, from the retro-orbital sinus plexuses of their eyes with the help of capillary tubes. ${ }^{25)}$ The blood was allowed to clot and centrifuged at $2500 \mathrm{rpm}$ in a refrigerated centrifuge at $10^{\circ} \mathrm{C}$ for $15 \mathrm{~min}$. The clear serum was isolated and stored at $0{ }^{\circ} \mathrm{C}$ until required for biochemical assays.

Serum Analysis The clear serum was used for the estimation of various blood chemical parameters including some serum enzymes like alkaline phosphatase (ALP), alanine transaminase (ALT), aspartate transaminase (AST), creatinine kinase (CK), and some other serum entities like high density lipoproteins (HDLP), urea, glucose, and potassium ion $\left(\mathrm{K}^{+}\right)$by the auto analyzer apparatus (Reflotron Plus, Roche, Germany) using commercially available Reflotron kits (Roche Diagnostics, Germany) for all the above parameters. The principle of the tests of each analytes were based on the methods as follows: $\mathrm{ALP}{ }^{26)} \mathrm{ALT}^{27)}{ }^{27} \mathrm{AST}^{28)} \mathrm{CK},{ }^{29)}$ HDLP, ${ }^{30)}$ urea and glucose, ${ }^{31)}$ and $\mathrm{K}^{+}{ }^{32)}$ However, briefly it can be said that Reflotron, is a solid phase reagent technology capable of measuring a wide range of analytes on whole blood, plasma or serum samples and the results show good concordance with conventional wet chemistry methods, with comparable imprecision. ${ }^{31)}$

Preparation of Erythrocyte Lysates Erythrocyte lysates were prepared by the method of Ceballos-Picot et $a l .{ }^{33)}$ Erythrocyte pellets were obtained from the blood samples by centrifugation at $2500 \mathrm{rpm}$ for $15 \mathrm{~min}$ at room temperature. The plasma and buffy coats were then removed, and the erythrocytes were washed twice in saline and stored at $-20^{\circ} \mathrm{C}$ for $15 \mathrm{~min}$. Lysed erythrocytes were prepared by thawing frozen samples and by the addition of 3 volumes of ice-cold distilled water. Cell membranes were removed by centrifugation at $1000 \boldsymbol{g}$ for $20 \mathrm{~min}$, and the supernatants were used for the estimation of antioxidant enzymes.

Reduced Glutathione Glutathione content was esti- mated according to the method of Ellman. ${ }^{34)}$ Briefly, $0.1 \mathrm{ml}$ of $25 \%$ trichloroacetic acid was added to $0.5 \mathrm{ml}$ of lysate. After protein precipitation by trichloroacetic acid, the samples were centrifuged to obtain the supernatant. Then, $0.1 \mathrm{ml}$ of supernatant was incubated with $2.0 \mathrm{ml}$ of freshly prepared $0.6 \mathrm{mmol} / 1$ 5,5-dithiobis(2-nitrobenzoic acid). Optical density of the yellow complex was measured at $412 \mathrm{~nm}$ against a reference lacking hemolysate. For each set of assays, a standard curve was obtained for reduced glutathione (GSH) and used to calculate GSH content in hemolysate from samples.

Lipid Peroxidation Lipid peroxidation (LPO) was assayed after the method of Ohkawa et al. ${ }^{35)}$ Briefly, a mixture of $8 \%$ solvent sodium dodecyl sulfate $(0.2 \mathrm{ml}), 0.9 \%$ TBA (thiobarbituric acid; $0.2 \mathrm{ml}$ ), and $20 \%$ acetic acid $(1.5 \mathrm{ml})$ was prepared, in which $0.2 \mathrm{ml}$ of hemolysate was added and the volume was made up to $4 \mathrm{ml}$ by adding distilled water. After boiling for $1 \mathrm{~h}$, the mixture was cooled, and $5 \mathrm{ml}$ of solution of $n$-butanol+pyridine (vol/vol $15: 1$ ) was added and then centrifuged at $1000 \times \boldsymbol{g}$ for $15 \mathrm{~min}$, and the absorbance in the supernatant was measured at $532 \mathrm{~nm}$ using spectrophotometer.

Protein Protein concentrations were measured by the method of Lowry et al. ${ }^{36)}$ Briefly, the samples were diluted with $100 \mathrm{mmol} / 1$ phosphate buffer $(\mathrm{pH} 7.5)$ to a volume of $0.5 \mathrm{ml}$. The reactions were diluted with $0.5 \mathrm{ml}$ of $1.0 \mathrm{~N}$ sodium hydroxide followed by the addition of $5.0 \mathrm{ml}$ of reagent mixture (containing $48 \mathrm{ml}$ of $2 \%$ sodium carbonate, $1 \mathrm{ml}$ of $1 \%$ copper sulfate, and $1.0 \mathrm{ml}$ of $2 \%$ sodium potassium tartarate). After $10 \mathrm{~min}$ of incubation at room temperature, the color was developed by the addition of $1.0 \mathrm{~N}$ Folin's reagent, and absorbance was measured using a spectrophotometer at $750 \mathrm{~nm}$.

Histopathology After blood collection, the rats were sacrificed by cervical dislocation. Their liver, kidney, heart, spleen and testis were washed gently in normal saline and their fresh weight was recorded. Thereafter, the liver and kidney were fixed in $10 \%$ neutral buffered formalin (NBF) for $24 \mathrm{~h}$ and rinsed with $70 \%$ ethanol, dehydrated in serial dilutions of ethanol before embedding in paraffin wax. Paraffin blocks of the tissues were sectioned at $5-6 \mu \mathrm{m}$ thickness in a rotary microtome. Sections were processed for staining with haematoxyllin and eosin for histopathological details. Photographs of the sections were taken at different magnifications in a Nikon Eclipse E600 Binocular Microscope, fitted with Nikon Digital Camera model DXM1200F, Japan.

Statistical Analysis Statistical analyses of the data were performed using Sigma Stat 3.1 software. Data are expressed as means \pm S.D. Statistical significance was determined by 1way analysis of variance (ANOVA), which was followed by Student-Newman-Keuls multiple comparison test. The significance levels were defined by $p \leq 0.05, p \leq 0.01$, and $p \leq 0.001$.

\section{RESULTS}

Body Weight Weights of the body and internal organs serve as a useful indicator of development. The present results clearly suggest that lithium consumption for seven weeks has a significant and dose-dependent depleting effect not only on the body weight (Fig. 1A) but also on the weight of the internal organs like kidney, heart, spleen, testis (Fig. 

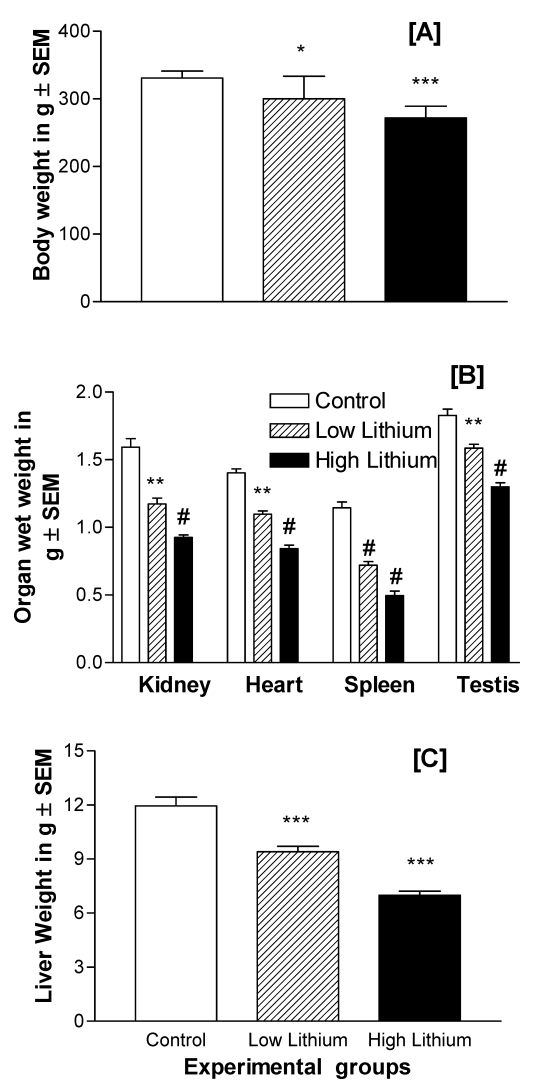

Fig. 1. Effect of Oral Consumption of Lithium Chloride $\left(\mathrm{LiCl}_{2}\right)$ by Male Rats on Their (A) Body Weight; (B) Organs Weight Like Kidney, Heart, Spleen, Testis and (C) Liver Weight

Fresh $\mathrm{LiCl}_{2}$ doses were available $24 \mathrm{~h}$ for a period of seven weeks. Weight of the body and internal organs were recorded on day one before starting the treatment and on the last day after total exposure period of seven weeks. $*, * *$ and $* * *$ or \# represent statistically significant $(p<0.05, p<0.01$ and $p<0.005$, respectively) by Newman Keul's Student's test through one way ANOVA. Doses of low and high lithium refer to 15 and $30 \mathrm{mg} \mathrm{Li} / \mathrm{kg}$ body weight, respectively.

1B) and liver (Fig. 1C). The dose-dependent effect of lithium is evident from the fact that the higher dose causes a highly significant $(p<0.005)$ loss whereas the lower dose causes a lesser significant loss in body and internal organs weights as compared to the controls (Fig. 1).

Blood Serum Chemistry Among the blood serum enzyme parameters (Fig. 2), it was observed that lithium treatment affected the level of enzymes ALP (Fig. 2A), ALT (Fig. 2B) and AST (Fig. 2C) significantly and dose-dependently.

Among the other blood serum parameters, lithium inhibited HDLP (Fig. 3A) as well as CK (Fig. 3B) significantly and dose-dependently. The levels of urea and glucose were found to be elevated significantly and dose-dependently (Fig. $3 \mathrm{~A}$ ). However, the level of $\mathrm{K}^{+}$was not affected by lithium at any doses (Fig. 3C).

Lipid Peroxidation Lipid peroxidation (LPO) levels showed a statistically significant $(p<0.001)$ and dosedependent increase after seven weeks of lithium treatment (Fig. 4A).

Reduced Glutathione The levels of reduced glutathione (GSH) activity was found to be dose-dependently and significantly $(p<0.001)$ decreased after lithium treatment (Fig. 4B).

Histopathological Observations The histopathological results show that lithium treatment caused significant and dose-dependent tissue damages in liver (Fig. 5) and kidney
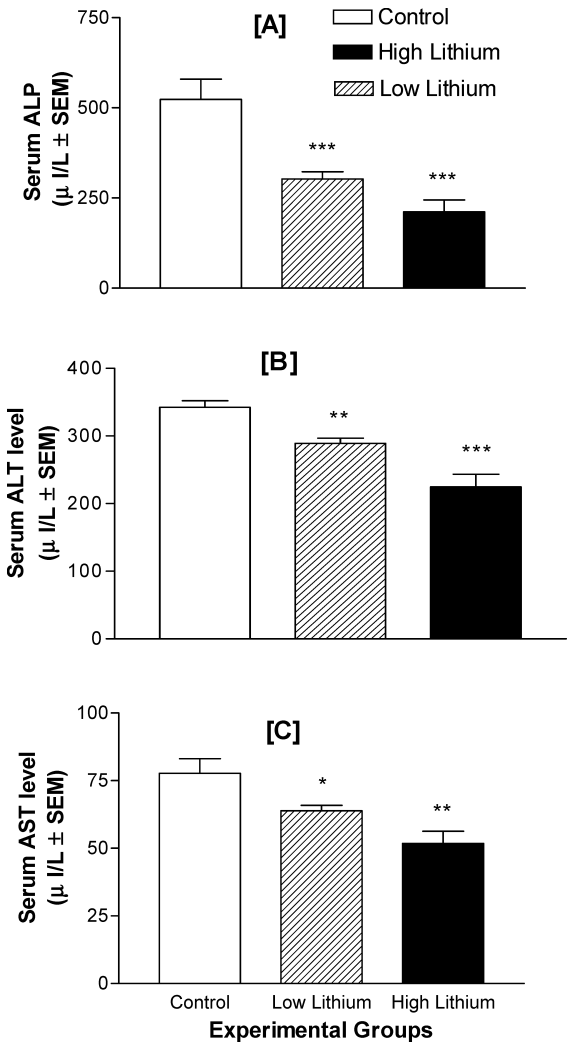

Fig. 2. Effect of Oral Consumption of Lithium Chloride $\left(\mathrm{LiCl}_{2}\right)$ by Male Rats on the Level of Their Serum (A) Alkaline Phosphatase (ALP), (B) Alanine Transaminase (ALT) and (C) Aspartate Transaminase (AST)

Fresh $\mathrm{LiCl}_{2}$ doses were available $24 \mathrm{~h}$ for a period of seven weeks. After exposure period the blood samples were collected from their retro-orbital sinus plexuses of eyes. After clotting the clear serum was used for enzyme estimations. *,** and *** represent statistically significant $(p<0.05, p<0.01$ and $p<0.005$, respectively) by Newman Keul's Student's test through one way ANOVA. Doses of low and high lithium refer to 15 and $30 \mathrm{mg} \mathrm{Li} / \mathrm{kg}$ body weight, respectively.

(Fig. 6). However, the representative tissues showed in the present figures are that of the treated groups at higher dose only with their respective controls.

At light microscopical level the rat liver of untreated control rats was found composed of a continuous compact field of hepatocytes interspersed with blood sinusoids and spotted with islands of connective tissue enclosing bile ducts, and venous and arterial vessels. The hepatocytes were radially organized in hepatic lobules, which in most cases were very tortuous and branched, with a large central vein. Close to the blood sinusoids, other structures were located like endothelial cells, bile canaliculi, and reticular fibers (Fig. 5A). Lithium exposed liver tissue was completely damaged and qualitative degenerative and necrotic changes were observed in the hepatocytes and central vein. The degenerated cells showed mild cytoplasmic vacuolation and blebbing. The necrosed cells showed coagulative and liquifactive type of necrosis. The sinusoidal spaces appeared to be expanded and furthermore, necrosed patches with hemorrhages and vacuoles were also visible frequently throughout the treated liver tissue (Fig. 5B).

The kidneys of the control group showed no histopathological changes and the bowman's capsular and renal spaces remained normal (Fig. 6A). However, the lithium treated kidney showed gross lesion of hemorrhages and milder to dark plum color appearance. The degenerated cells showed cyto- 

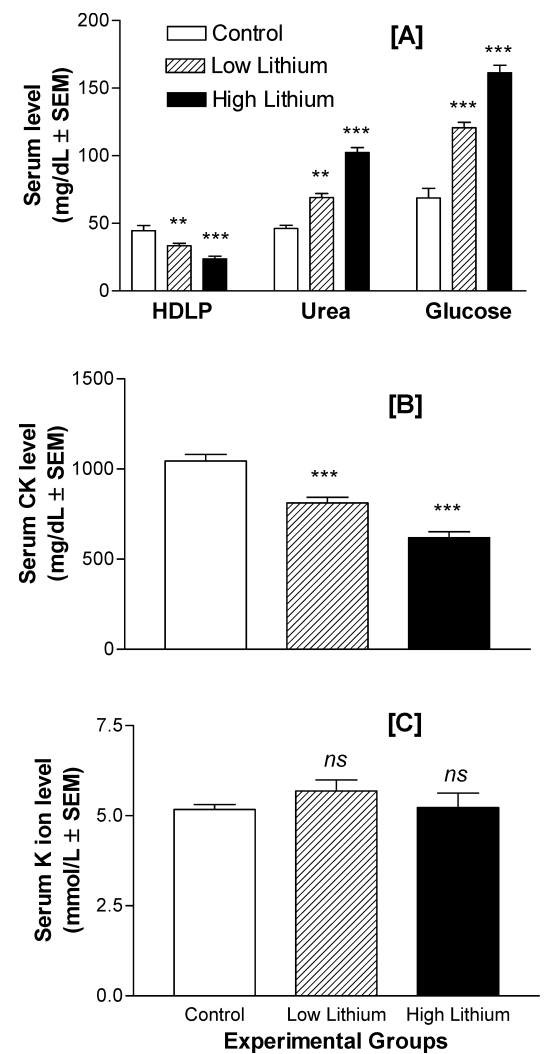

Fig. 3. Effect of Oral Consumption of Lithium Chloride $\left(\mathrm{LiCl}_{2}\right)$ by Male Rats on the Level of Their Serum (A) High Density Lipoproteins (HDLP), Urea and Glucose, (B) Creatinine Kinase (CK) and (C) Potassium Ion (K Ion)

Fresh $\mathrm{LiCl}_{2}$ doses were available $24 \mathrm{~h}$ for a period of seven weeks. After exposure period the blood samples were collected from their retro-orbital sinus plexuses of eyes. After clotting the clear serum was used for enzyme estimations. ** and $* * *$ represen statistically significant ( $p<0.01$ and $p<0.005$, respectively) by Newman Keul's Student's test through one way ANOVA. ns represents statistically not significant. Doses of low and high lithium refer to 15 and $30 \mathrm{mg} \mathrm{Li} / \mathrm{kg}$ body weight, respectively.

plasmic vacuolation and blebbing. Necrosis of the convoluted distal and proximal tubules was noticed in abundance and the renocytes of these tubules showed hydropic and fatty degeneration of the cells. The bowman's capsular spaces were expanded due to shrinkage of the glomeruli cells (Fig. $6 \mathrm{~B})$.

\section{DISCUSSION}

In present study, the activities of AST and ALT were significantly decreased in serum of lithium treated rats, which might be due to the liver dysfunction resulting into disturbance in the biosynthesis of these enzymes with alteration in the permeability of liver membranes. Phosphatases including ALP are important and critical enzymes in biological processes and are responsible for detoxification, metabolism and biosynthesis of energetic macromolecules for different essential functions. Any interference in these enzymes leads to biochemical impairment and lesions of the tissue and cellular function ${ }^{37)}$ and it was suggested that interference in the activities of ALP enzyme in serum might be due to the altered permeability of plasma membrane or cellular necrosis, and thus showing the stress condition of the treated animals. Also, Rahman et al $^{37)}$ reported that the altered level of these enzymes in blood might be due to the necrosis of liver, kid-
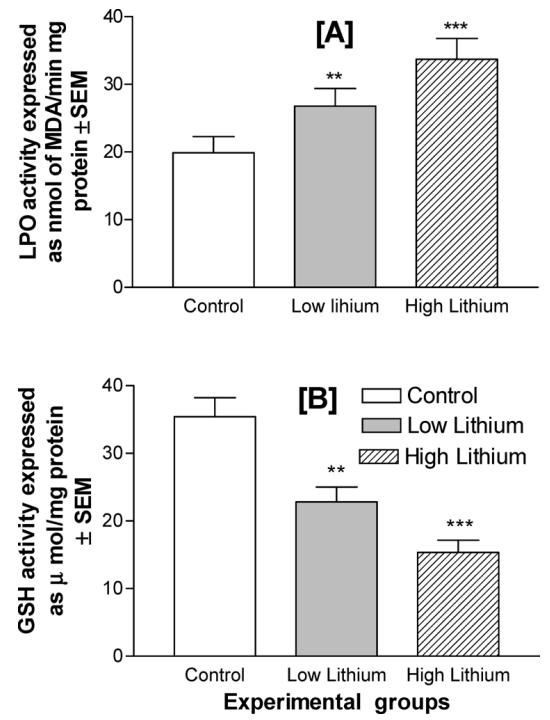

Fig. 4. Effect of Oral Consumption of Lithium Chloride $\left(\mathrm{LiCl}_{2}\right)$ by Male Rats on the Antioxidant Enzymes (A) Lipid Peroxidation (LPO), Activity Expressed as nmol of $\mathrm{MDA} / \mathrm{min}$ mg Protein; (B) Reduced Glutathione (GSH), Activity Expressed as $\mu \mathrm{mol} / \mathrm{mg}$ Protein; in Their Erythrocyte Lysates

Fresh $\mathrm{LiCl}_{2}$ doses were available $24 \mathrm{~h}$ for a period of seven weeks. After exposure period the blood samples were collected from their retro-orbital sinus plexuses of eyes. The washed erythrocytes were lysed and their clear supernatants were used for the assay of LPO and GSH. ** and *** represent statistically significant $(p<0.01$ and $p<0.005$, respectively) by Newman Keul's Student's test through one way ANOVA. Doses of low and high lithium refer to 15 and $30 \mathrm{mg} \mathrm{Li} / \mathrm{kg}$ body weight, respectively.

ney and lung. ALP is involved in transphosphorylation reaction and cell autolysis functions, thus, a loss in serum ALP reflected the cytotoxic effects of lithium. Various histopathological anomalies like vacuolization, degeneration of cells and inflammation of the conducting tubules, induced by the lithium, in kidney, are in agreement with the results in uranyl acetate fed mammals. ${ }^{38)}$ The development of cytoplasmic vacuoles and necrosis in proximal convoluted tubules, glomerular shrinkage, tubular necrosis and loss of cellular integrity due to lithium exposure has been observed earlier also during lithium therapy. ${ }^{39)}$ The results of our study are consistent with the previous finding of Lepkifker et al. ${ }^{40)}$ in which renal damages in long term lithium treatment has also been reported. The blood serum enzymes like ALP, AST and ALT can be used as biomarker enzymes for detecting lithium toxicity besides measuring the level of lithium itself in various tissues. Generally and logically such tissue damages should result in a leak of the studied enzymes from the damaged tissues in the serum but on the contrary the serum enzymes are observed to decrease in the present study. It is well supported by documentary evidences that lithium treatment causes increased water consumption, ${ }^{41)}$ however, in the present study lithium dissolved in water formed the only source of drinking fluid throughout the exposure period and no fresh water was allowed for consumption. Although actual consumption of water was not observed in the present study, it might be of interest to investigate in a separate study the causes for a decrease in the serum level of ALP, ALT and AST due to lithium exposure in perspective to normal water consumption. Similar decreased serum enzymes have been reported in mammals exposed to mercury salt. ${ }^{42)}$ However, in rainbow trout, the toxicity of lithium chloride has been shown to 

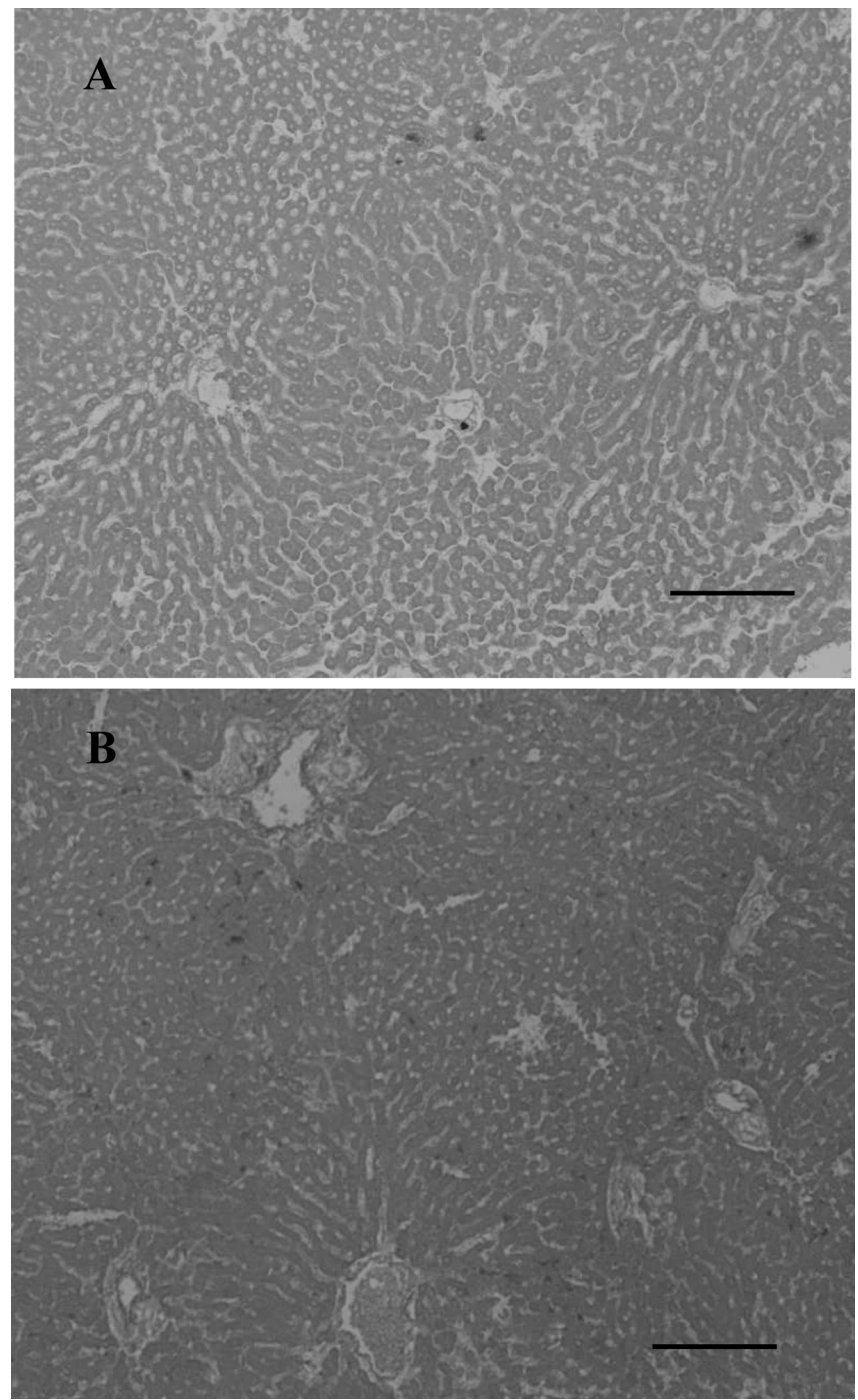

Fig. 5. Effect of Oral Consumption of Lithium Chloride $\left(\mathrm{LiCl}_{2}\right)$ by Male Rats on the Histopathological Structures of Liver

(A) Control untreated rats showing normal histological structures. (B) Treated rats with high dose of $\mathrm{LiCl}_{2}(30 \mathrm{mg} / \mathrm{kg}$ body weight $)$ showing significant necrotic and degenerative tissue damages. Fresh $\mathrm{LiCl}_{2}$ doses were available $24 \mathrm{~h}$ for a period of seven weeks. After exposure period and after blood collection the rats were sacrificed by cervical dislocation. Liver was fixed in $10 \%$ neutral buffered formalin and $5-6 \mu \mathrm{m}$ paraf fin embedded sections were stained with haematoxyllin and eosin and permanent slides were observed in Nikon Eclipse E600 Binocular Microscope, Japan. Bar magnification $=50 \mu \mathrm{m}$.

cause a reduction of adenosine triphosphatase (ATPase), citrate synthase, free fatty acids and cholesterol in the gills and plasma. $^{43)}$

Besides the soluble enzymes of blood serum like AST, ALT and ALP, the other observed indices of blood chemistry in the present study may also prove to be suitable bioindicators for detecting hepatic and renal damages due to lithium toxicity. As blood is the overall reflector of body health, the altered level of the glucose, urea and HDLP in treated rats are suggestive of some degree of hepatic and renal damages. Significant elevation in blood urea and decrease in serum proteins (serum enzymes) seems related to the observed kidney damage. An increase up to 30 to $60 \%$ urinary excretion of proteins associated with decreased serum proteins has also been reported in mammals intoxicated with mercury salt. ${ }^{42}$ Hypercholesterilaemia in animals reflects the disturbed car-
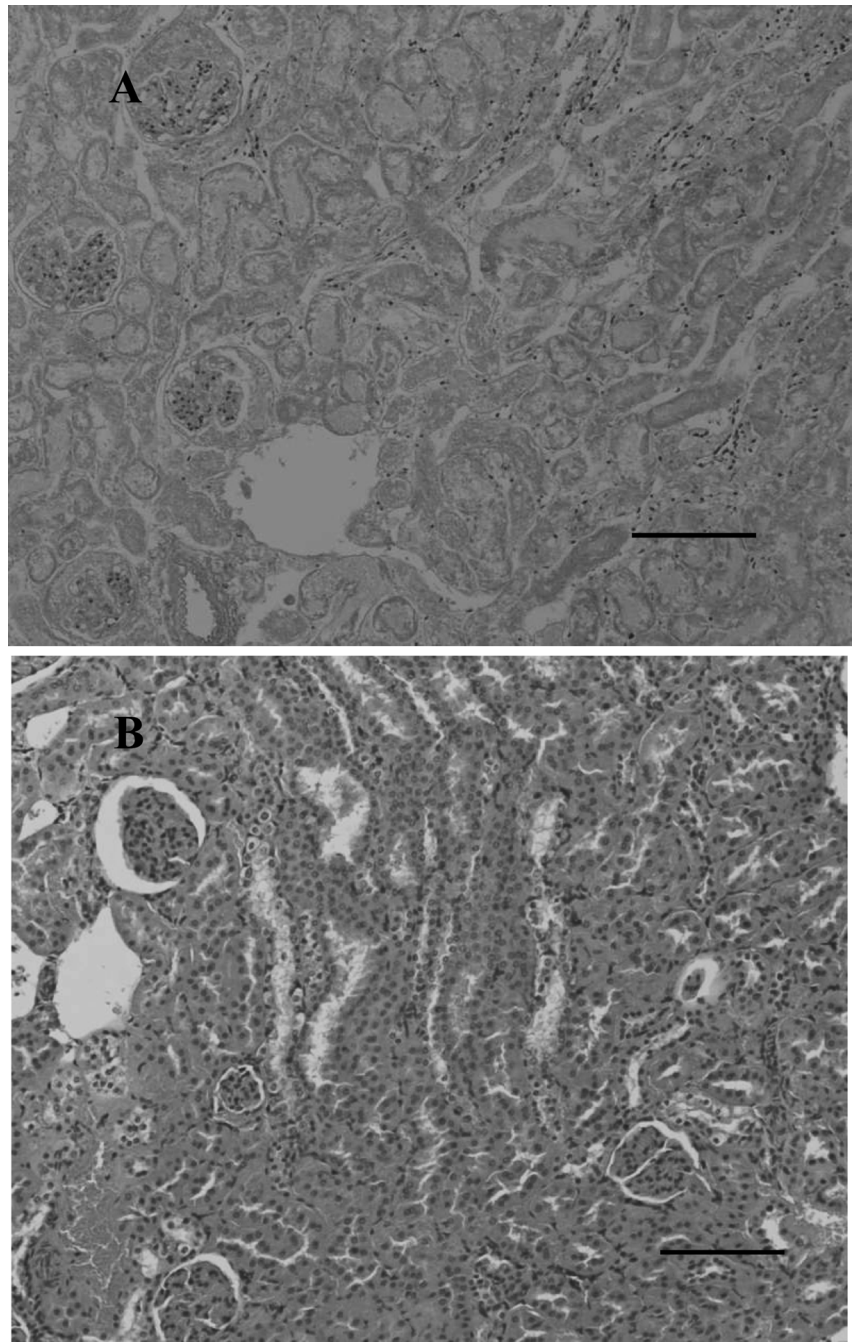

Fig. 6. Effect of Oral Consumption of Lithium Chloride $\left(\mathrm{LiCl}_{2}\right)$ by Male Rats on the Histopathological Structures of Kidney

(A) Control untreated rats showing normal histological structures. (B) Treated rats with high dose of $\mathrm{LiCl}_{2}(30 \mathrm{mg} / \mathrm{kg}$ body weight $)$ showing significant gross lesion of hemorrhages with necrotic and degenerative tissue damages. Fresh $\mathrm{LiCl}_{2}$ doses were available $24 \mathrm{~h}$ for a period of seven weeks. After exposure period and after blood collection the rats were sacrificed by cervical dislocation. Kidney was fixed in $10 \%$ neutral buffered formalin and 5-6 $\mathrm{m}$ paraffin embedded sections were stained with haematoxyllin and eosin and permanent slides were observed in Nikon Eclipse E600 Binocular Microscope, Japan. Bar magnification $=50 \mu \mathrm{m}$.

bohydrate metabolism. Rise in serum glucose level may be due to the pancreatic manifestations (insulin insufficiency). Earlier observations made with laboratory animals following lithium nitrate intoxication, the glycogen content in the liver and kidney was found decreased ${ }^{44}$ ) along with a marked increase in blood glucose. ${ }^{45}$ One possible reason for the increase in serum glucose level in the present study, may be that lithium interferes with the carbohydrate metabolic clock of gluconeogenesis and glycogenolysis, due to which the serum level of sugar increases.

The present study was also designed to assess the antioxidative defense system in the RBCs of lithium-treated rats. Lithium treatment resulted in a dose-dependent and significant increase in LPO and decrease in the levels of GSH in the RBCs. The present finding supports the earlier report of lithium induced oxidative stress in the rat blood cells. ${ }^{13)} \mathrm{Re}-$ duced glutathione (GSH) is central to the cellular antioxidant defenses and acts as an important cofactor for antioxidant en- 
zymes. ${ }^{46)}$ Under oxidative stress, glutathione is consumed by the glutathione-related enzymes to detoxify peroxides produced because of increased LPO, ${ }^{47,48}$ and elevation in LPO is a consequence of depleted GSH stores, which are otherwise capable of moderating the amount of LPO. Similar lithium oral induced disturbances in the antioxidant barrier (involving glutathione peroxidase and superoxide dismutase) has been shown in the rat serum and tissues where the increment of one enzyme was accompanied with the depletion of the other. $^{49)}$

In conclusion, our results suggest that lithium induces hepatic and renal toxicity in rats at physiological and histopathological levels. It has the potential of inducing adverse effects in the rat blood and oxidative stress in the rat RBCs also. However, toxicity in other organs like testis, spleen and heart cannot be ruled out. Although, the precise mechanism of lithium toxicity still remains incompletely understood, the clinical use of lithium needs a careful and cautious attention.

\section{REFERENCES}

1) Grimes C. A., Jope R. S., Prog. Neurobiol., 65, 391-426 (2001).

2) Chuang D. M., Chen R. W., Chalecka-Franaszek E., Ren M., Hashimoto R., Senatorov V., Kanai H., Hough C., Hiroi T., Leeds P., Bipolar Disord., 4, 1—9 (2002).

3) Lenox R. H., Hahn C. G., J. Clin. Psychiatry, 61, 5-15 (2000).

4) Zarnescu O., Zamfirescu G., Int. J. Androl., 29, 576-582 (2006).

5) Sharma S. D., Iqbal M., Biol. Pharm. Bull., 28, 834-837 (2005).

6) Ilagan M. C., Carlson D., Madden J. F., Del. Med. J., 74, 263-270 (2002).

7) Bourgeois J. A., J. Am. Opt. Assoc., 62, 548-551 (1991).

8) Davies N. L., J. Soc. Afr. Vet. Assoc., 62, 140-142 (1991).

9) Hensen J., Haenelt M., Gross P., Nephrol. Dial. Trans., 11, 622-627 (1996).

10) Rosenthal M. E., Goodwim F. K., Annu. Rev. Med., 33, 555-556 (1982).

11) Dhawan D., Mehta J., Kumar R., Chopra J. S., Sharma R., Digestion, 36, 184-190 (1987).

12) Phiel C. J., Klein P. S., Annu. Rev. Pharmacol. Toxicol., 41, 789-813 (2001).

13) Malhotra A., Dhawan D. K., Nutr. Res., 28, 43-50 (2008).

14) Bartha L., Marksteiner J., Bauer G., Benke T., Cortex, 38, 743-752 (2002).

15) Wolf M. A., Louis J. C., Vincendon G., Prog. Neuropsychopharmacol. Biol. Psychiatry, 13, 765-773 (1989).

16) Casado M., Aragón M., Giménez C., Neurochem. Res., 14, 905-908 (1989).

17) Ghoshdastidar D., Int. J. Exp. Biol., 28, $444-450$ (1999).

18) Loghin F., Olinic A., Popa D. S., Socaciu C., Leucuta S. E., Met. Based Drugs, 6, 87-93 (1999).

19) Zhang Y., Nelson R. D., Carlson N. G., Kamerath C. D., Kohan D. E., Kishore B. K., Am. J. Physiol. Renal. Physiol., 296, 1194-1201 (2009).
20) Chadha V. D., Bhalla P., Dhawan D. K., Liver Int., 28, 558-565 (2008).

21) Sahin O., Sulak O., Yavuz Y., Uz E., Eren I., Ramazan Yilmaz H., Malas M. A., Altuntas I., Songur A., Pathology, 38, 58-62 (2006).

22) Bhalla P., Chadha V. D., Dhar R., Dhawan D. K., Indian J. Exp. Biol., 45, 954-958 (2007).

23) Pettegrew J. W., Short J. W., Woessner R. D., Strychor S., McKeag D. W., Armstrong J., Minshew N. J., Rush A. J., Biol. Psychiatry, 22, 857-871 (1987).

24) Lima T. Z., Blanco M. M., Santos Junior J. G., Coelho C. T., Mello L. E., Rev. Bras. Psiquiatr, 30, 215-221 (2008).

25) Sorg D. A., Buckner B., Proc. Sec. Exp. Med., 115, 1131-1132 (1964).

26) Schumann G., Dominick H. C., Hellmann D., Klauke R., Möckesch M., Stekel H., von Schenck H., Kraft M., Nagel R., Hänseler E., Clin. Chem. Lab. Med., 39, 71-78 (2001).

27) Deneke U., Rittersdorf W., Clin. Chem., 30, 921 (1984).

28) Deneke U., Rittersdorf W., Werner W., Clin. Chem., 31, 1009 (1985).

29) Horder M., Jorgensen P. J., Hafkenscheid J. C., Carstensen C. A., Bachmann C., Bauer K., Neuwald C., Rosalki S. B., Foo A. Y., Vogt W., Eur. J. Clin. Chem. Clin. Biochem., 29, 691-696 (1991).

30) Kinlay S., Med. J. Aust., 149, 126-129 (1988).

31) Price C. P., Koller P. U., J. Clin. Chem. Clin. Biochem., 26, 233-250 (1988).

32) Paschen K., Hagemann P., Lang H. R., Cortes M., Weidemann G., Toffaletti J., Burritt M., Leinberger R., Tritschler W., Ramstetter E., Eur. J. Clin. Chem. Clin. Biochem., 31, 545-552 (1993).

33) Ceballos-Picot I., Triever J. V., Nicole A., Silnet P. M., Thevenin M., Clin. Chem., 38, 66-70 (1992).

34) Ellman G., Arch. Biochem. Biophys., 82, 70-77 (1959).

35) Ohkawa H., Ohisshi N., Yagi K., Anal. Biochem., 95, 351-358 (1979).

36) Lowry O. H., Rosebrough N. J., Farr A. L., Randall R. J., J. Biol. Chem., 193, 265-275 (1951).

37) Rahman M. F., Siddiqui M. K., Jamil K., Drug Chem. Toxicol., 23, 497-509 (2000).

38) Goel K. A., Garg V., Garg V. K., Environ. Contam. Toxicol., 24, 9-12 (1980).

39) Markowitz G. S., Radhakrisnan J., Kambham N., Valeri A. M., Hines W. H., D'Agati V. D., Am. Soc. Nephrol., 11, 1439-1449 (2000).

40) Lepkifker E., Sverdlik A., Iancu I., Ziv R., Segev S., Kotler M., Clin. Psychiatry, 65, 850-856 (2004).

41) Hines G., Henslee D. F., Psychopharmacology, 90, 236-238 (1986).

42) Singhal R. L., Kacew S., Sutherland D. J. B., Env. Res., 7, 220-229 (1974).

43) Tkatcheva V., Franklin N. M., McClelland G. B., Smith R. W., Holopainen I. J., Wood C. M., Arch. Environ. Contam. Toxicol., 53, $632-638$ (2007).

44) Goel K. A., Sharma S. D., Maya S., Arh. Rada. Hyg. Toksikol., 36, $249-253$ (1985).

45) Sharma O. P., Makkar H. P. S., Dawra R. K., Negi S. S., Toxicol. Lett., 9, 73-76 (1982).

46) Hayes J. D., Flangan J. U., Jowsey I. R., Annu. Rev. Pharmacol. Toxicol., 45, 51-88 (2005).

47) Cathcart R. F., Med. Hypotheses, 18, 61-77 (1985).

48) Yu B. P., Physiol. Rev., 74, 139-165 (1994).

49) Kielczykowska M., Pasternak K., Musik I., Wroniska J., Ann. Univ. Mariae Curie Sklodowska Med., 59, 140-145 (2004). 